\title{
Transcatheter aortic valve implantation for severe aortic stenosis
}

\author{
Ankit Garg MD, Subodh Verma MD PhD
}

Cite as: CMAJ 2019 February 4;191:E134. doi: 10.1503/cmaj.180976

1 Transcatheter aortic valve implantation is first-line therapy for high-risk patients with severe symptomatic aortic stenosis Transcatheter aortic valve implantation reduces risk of death in patients for whom the risk of surgical aortic valve replacement is prohibitive ${ }^{1}$ and has similar rates of survival in patients who are considered at high risk of complications or death from surgery. ${ }^{2}$ Candidates should have a life expectancy greater than 1 year and expect to have a meaningful improvement in quality of life. ${ }^{3}$ Candidates should undergo risk assessment by a comprehensive heart team that includes interventional cardiologists, cardiac surgeons and anesthesiologists. ${ }^{3}$ Several risk scores are used to assess surgical risk, but major risk factors such as frailty and medical comorbidities should be considered as part of risk stratification (Box 1$).^{3}$

2

The procedure should be performed at a dedicated centre of excellence specializing in treatment of valvular heart disease There is strong evidence suggesting that the rate of complications after transcatheter aortic valve implantation is dependent on the volume of these procedures performed, with the highest-volume centres having the lowest rate of complications. ${ }^{4}$

There are unique postoperative risks associated with transcatheter aortic valve implantation

The implantation procedure carries an increased risk of paravalvular regurgitation (6.1\%-15.5\%); major vascular access complications, such as retroperitoneal hematoma (6\%-32\%); and conduction disease (6.6\%-38.7\%). ${ }^{5}$ Patients who develop new left bundle branch block after transcatheter aortic valve implantation should undergo continuous electrocardiogram monitoring for 48-72 hours and be considered for further monitoring or permanent pacemaker implantation if conduction abnormalities persist. ${ }^{6}$

While thromboprophylaxis is recommended after transcatheter valve replacement, the choice of therapy is controversial

TAVI valves are bioprosthetic and valve thrombosis is uncommon. Although evidence is sparse, a current guideline recommends dual antiplatelet therapy for 3 to 6 months in patients without other indications for anticoagulation. ${ }^{3}$

Routine endocarditis prophylaxis is recommended for patients with an implanted transcatheter aortic valve

Prophylaxis against infective endocarditis is recommended before highrisk and dental procedures that involve manipulation of the oral mucosa, gingival or periapical region of the teeth (Box 1$).^{3}$

\section{Box 1: Resources for clinicians}

- Society of Thoracic Surgeons Online Risk Calculator: http://riskcalc.sts.org/ stswebriskcalc/\#/

- European System for Cardiac Operative Risk Evaluation (EuroSCORE) II calculator: http:// euroscore.org/calc.html

- American Association of Endodontists Antibiotic Prophylaxis 2017 Update: https://www.aae.org/ specialty/wp-content/uploads/sites/2/2017/06/ aae_antibiotic-prophylaxis-2017update.pdf

\section{References}

1. Leon MB, Smith C, Mack M, et al. Transcatheter aortic-valve implantation for aortic stenosis in patients who cannot undergo surgery. N Engl J Med 2010;363:1597-607.

2. Smith CR, Leon M, Mack M, et al. Transcatheter versus surgical aortic-valve replacement in high-risk patients. N Engl J Med 2011;364:2187-98.

3. Falk V, Baumgartner H, Bax JJ, et al. 2017 ESC/EACTS guidelines for the management of valvular heart disease. Eur J Cardiothorac Surg 2017;52:616-64

4. Badheka AO, Patel NJ, Panaich SS, et al. Effect of hospital volume on outcomes of transcatheter aortic valve implantation. Am J Cardiol 2015;116:587-94.

5. Siontis GC, Praz F, Pilgrim T, et al. Transcatheter aortic valve implantation vs. surgical aortic valve replacement for treatment of severe aortic stenosis: a meta-analysis of randomized trials. Eur Heart J 2016;37:3503-12.

6. Auffret V, Puri R, Urena M, et al. Conduction disturbances after transcatheter aortic valve replacement. Circulation 2017; 136:1049-69.

Competing interests: None declared.

This article has been peer reviewed.

Affiliations: Department of Medicine (Garg), University of Toronto; Division of Cardiac Surgery (Verma) St. Michael's Hospital, Toronto, Ont.

Correspondence to: Ankit Garg, ankit.garg@medportal.ca 